\title{
Stochastic Production and Heterogeneous Risk Preferences: Commercial Fishers' Gear Choices
}

\author{
Håkan Eggert ${ }^{1}$ \\ Ragnar Tveterås
}

\author{
Working Papers in Economics no. 54 \\ September 2001 \\ Department of Economics \\ Göteborg University
}

\begin{abstract}
As long as total effort cannot be completely controlled, a more thorough understanding of fishers' supply response decisions will be beneficial for fishery managers. In this paper, we present a model of fishers' gear choice, which is empirically estimated on a panel of Swedish demersal trawlers. The approach allows for heterogeneity both in production technology and in risk preferences. Stochastic revenue functions with fixed effects are estimated and used to predict expected revenue and standard deviation for each trip. We employ a linear utility function in the mean-standard deviation framework and then analyze the gear choices, using the predicted values together with vessel capacity and lagged variables for the previous trip in a random parameters-logit model, which allows for heterogeneous risk preferences. The results indicate that fishers have a strong tendency to choose the same gear used on the previous trip, while in general they react to changes in economic and biological conditions by responding positively to increases in expected landing values and negatively to increases in the variability of the expected landing values, indicating risk aversion.
\end{abstract}

Keywords: Risk preferences, two-moment decision models, Just-Pope production function, random-parameters logit, Swedish fisheries

JEL classification: D81; Q22

This work was sponsored, by the Swedish Council for Forestry and Agricultural Research, and by the Sustainable Coastal Zone Management Programme, funded by the Foundation for Strategic Environmental Research, MISTRA. Assistance in preparing the data set by Bernt Johnsson, and Peter Martinsson is gratefully acknowledged. We have benefited from discussions with Fredrik Carlsson on various aspects of this paper. Comments from David Layton, Jens Petter Gitlesen, Marcus Asplund and Olof Johansson-Stenman are gratefully acknowledged.

${ }^{1}$ Department of Economics, Göteborg University, Box 640, SE 40530 Göteborg, Sweden. E-mail: Hakan.Eggert@economics.gu.se

2 Stavanger University College, Department of Business Administration, P.O. Box 2557, Ullandhaug, N4091 Stavanger, Norway. E-mail: ragnar.tveteras@oks.his.no 


\section{Introduction}

In classical fishery economics most attention was given to long-run investment decisions. The basic assumption has been that fishing effort will adjust instantaneously by reallocating to the most profitable fisheries and withdrawing from those, which are non-profitable (Warming, 1911; Gordon, 1954). Later work has refined this assumption by relating the adjustment speed to the level of profits or losses (Smith, 1968; Wilen, 1976). However, these models have dealt with single species fisheries and focused on optimal solutions with implicit assumptions of complete control of effort. In reality, fisheries are often multi-species, not perfectly enforced, and fishers may not solely focus on maximizing expected profits, as they have to deal with a considerable level of risk. So far, little attention has been given to the microeconomic decision environment that modern fishers are faced with. A prominent exception is the research on behavioral modeling of fisheries that was initiated by Bockstael and Opaluch (1983). Instead of focusing on the optimal solutions, the assumption of perfectly controlled effort is relaxed and the focus is on fishers' supply response decisions. The simple premise that vessels will immediately reallocate to the most profitable grounds and even-out profits across grounds are erroneous in many cases (Holland and Sutinen, 2000). Analogously, the impact of traditional regulation measures aimed at relieving the fishing pressure of an over-exploited stock may be reduced due to an inertia effect where fishers do not reallocate despite worsened conditions for the particular species. Fishers' response to different changes will also depend on their risk preferences (Mistiaen and Strand, 2000). If a particular target species yields high, expected profits with high variability, the welfare consequences from a temporary closed season of this species will vary depending on whether fishers are risk averse or risk loving. Temporary closure is a common strategy in fisheries management, and in January 2001, the European Union and Norway agreed upon a 10-weeks closure of demersal trawling for cod in the North Sea, including the fishing grounds in this study. A better understanding of fisher response to various changes, whether in biological, regulatory, or economic terms, is precursory to the development of any successful management regime.

In the present paper, we study the gear choice decisions of the Swedish West coast demersal trawl fishers. Stochastic revenue functions with fixed effects are 
specified and estimated for the different gear. The estimated coefficients are used to generate predicted revenues and predicted standard deviations of revenue for all potential gear for each trip of each fishing vessel. We apply a linear utility function in the mean-standard deviation framework, where risk attitudes are independent of initial level of wealth. The predicted figures and the actual choices are then analyzed in a random-parameters logit model, which, given the chosen utility function, can accommodate heterogeneous risk preferences. Results indicate that fishers respond positively to increases in expected revenues, and that a great majority of the fishers are risk averse, but that a strong inertia effect exists for using the same gear as for the previous trip.

\section{Demersal Trawl Fishery}

The Swedish West Coast demersal trawl fleet targets several species of which Norway lobster, shrimp and cod are the most important. The fleet, consisting of almost 300 vessels, produced an ex-vessel landing value of $\mathrm{SEK}^{3} 470$ million or more than $50 \%$ of total Swedish landings in 1995. Both Norway lobster and shrimp can be seen as nonmigratory species at their catchable size, i.e. they are caught on specific bottoms that fishers learn to identify. Due to their behavior, the same often applies to demersal fish species, 4 despite the fact that some species, like cod, may be migratory. Norway lobster and Northern shrimp are more easily caught on different depths depending on changes in environmental conditions, such as wind, light intensity, water temperature, and current. These facts imply that fishers have similar search behaviors irrespective of what species they target (personal communication, Mats Ulmestrand, Institute of Marine Research, Sweden). Each commercially important species has an overall total allowable catch (TAC) quota and a specific gear regulation. The gear regulations include different minimum sizes of the trawl mesh and a general upper limit of $70 \%$ by-catch of other species. In 1995, 290 vessels recorded landings using demersal trawls. Some vessels

\footnotetext{
${ }^{3}$ US\$ 1 = SEK 10 (March, 2001)

${ }^{4}$ Fishers target several species when they set the demersal fish trawl, cod being the most important. For simplicity, demersal fish trawl is hereafter referred to as cod trawl.
} 
choose to specialize in one species, and others alternate between two species, while a few vessels use all three different trawls during the year. All three alternatives may not be available to a vessel, e.g. due to vessel size or simply because the vessel owner has not invested in the necessary gear. The Swedish fisheries are managed under the Council of the EU since Swedish membership in January 1, 1995, but the Swedish Board of Fisheries and the Swedish Coastguard carry out the monitoring and enforcement. Commercial fishing requires a vessel license, which in turn requires a personal license held by a minimum of one crew member. The enforced and restrictive regulations are; a) the maximum $70 \%$ by-catch rule, b) a minimum landing size for shrimp, Norway lobster, and cod, c) a minimum trawl mesh size of 60,70 , and $90 \mathrm{~mm}$, respectively, and d) a TAC for the commercially important species. The TACs for Norway lobster, shrimp, and demersal fish have not been binding during the 1990s. In broader terms, the Swedish West Coast demersal trawl fishery in 1995 can be characterized as an open access fishery, which suffers from over-capitalization and low profitability (Eggert and Ulmestrand, 1999; Eggert, 2000).

\section{Methodology, Model, and Data}

There are a limited number of papers on fishery and location choice on which we build (Bockstael and Opaluch, 1983, Eales and Wilen, 1986, Dupont, 1993, Ward and Sutinen, 1994, Holland and Sutinen, 1999 and 2000; Mistiaen and Strand, 2000). However, in several respects we differ in our approach compared to the previous work. In the following section we introduce the Just-Pope production function and its advantages when modeling production under risk and note that it meets the requirements of the mean-standard deviation (MS) framework. We discuss discrete choice analysis and propose a linear MS utility function, which -combined with a random-parameters logit model- allows for heterogeneous risk preferences among fishers. Last, we discuss the data set used to estimate the models. 


\section{Just-Pope Production Function}

A central concern in this paper is how to model the fishers' expectation formation on revenue when they make their gear choices. We hypothesize that Swedish fishers take into account both the expected revenue and revenue risk when they make their choices. Fisheries are characterized by substantial production risk, which is the main source of revenue risk at the trip level. Price risk can be regarded as a less important source of revenue risk for individual trips, since fishers usually have information on prevailing market prices prior to the trip, and these prices may not change much during the trip. Hence, for empirical modeling purposes we assume that prices are non-stochastic and exogenous. Standard production function specifications are made without regard to risk considerations, and consequently estimates based on these are uninformative with respect to the structure of risk in the production technology (Just and Pope, 1978). We apply the framework outlined by Just and Pope (1978) (hereafter JP) to model production risk. The JP production function is given by

$$
y=g(\mathbf{x})+u=g(\mathbf{x})+h(\mathbf{x})^{1 / 2} \varepsilon,
$$

where $\mathbf{x}$ is a vector of $K$ inputs, $g(\cdot)$ is the mean function (or deterministic part), $h(\cdot)$ is the variance function (or risk part), and $\varepsilon$ is the exogenous production shock with $\mathrm{E}(\varepsilon)=0$ and $\operatorname{Var}(\varepsilon)=\sigma_{\varepsilon}{ }^{2}$. We see that the input vector $\mathbf{x}$ influences both mean output and output risk, because $E(y)=g(\mathbf{x})$ and $\operatorname{var}(y)=\operatorname{var}(u)=h(\mathbf{x}) \sigma_{\varepsilon}^{2}$. One of the central requirements JP propose for specifications of risky production technologies is that there should be no a priori restrictions on the risk effects of inputs, i.e. $\partial[\operatorname{var}(y)] / \partial x_{k}=$ $\partial h(\cdot) / \partial x_{k} \Leftrightarrow>0$ should all be possible. In $^{\text {In }}$ other words, the production function should be general enough to accommodate both increasing and decreasing output risk in inputs.

In expected utility (EU) models, producers choose the input vector $\mathbf{x}$ which maximizes their expected utility based on observed (or expected) output and input prices $(p, \mathbf{w})$ and a priori knowledge of the structure of the risky production technology. Given our assumptions, the expected utility can be written as

$$
E U=g(E(\pi), \operatorname{Var}(\pi)) \text {, }
$$

\footnotetext{
${ }^{5}$ See Just \& Pope (1978) for other requirements for a risky production technology.
} 
where $\mathrm{E} \pi(\cdot)$ is mean profit and $\operatorname{Var} \pi(\cdot)$ is the variance of profit. The function $\mathrm{g}$ represents the fisher's subjective trade-off between mean profit (output) and variance of profit (output). For all fishers utility increases in profit $(d U / d E \pi(\cdot)>0)$, and for risk averse fishers utility declines in profit risk $(d U / d \operatorname{Var} \pi(\cdot)<0)$. The condition for using a Mean-Standard deviation (MS) representation is that the members of the choice set differ only by location and scale parameters (Meyer 1987; Levy 1989). Under a JustPope production technology, which is used here, the location and scale condition holds (Leathers and Quiggin, 1991). Hence, under a Just-Pope production technology the expected utility maximization problem $\max _{\mathbf{x}} \mathrm{E} U(\pi(\mathbf{x}))$ is equivalent to the $\mathrm{MS}$ maximization problem

$$
\max _{\mathbf{x}} V(\mu, \sigma),
$$

where $\mu=\mathrm{E} \pi=p \cdot f(\mathbf{x})-\mathbf{w}^{\prime} \mathbf{x}$, and $\sigma=p \cdot h(\mathbf{x}) \sigma_{\varepsilon}$.

There is a positive linear relationship between the moments of output and the moments of profit under JP production risk (2), with the mean and variance of profit given by

$$
\mathrm{E} \pi=p \cdot \mathrm{g}(\mathbf{x})-\mathbf{w}^{\prime} \mathbf{x}=p \cdot \mathrm{E} y-\mathbf{w}^{\prime} \mathbf{x} \text {, and }
$$$$
\operatorname{Var} \pi=p^{2} \cdot \operatorname{Var} y \text {. }
$$

In case of risk affinity (i.e. $\mathrm{d} U / \mathrm{d} \operatorname{Var} \pi>0$ ), the producer regards the variability in actual landings as something good. The chance of striking gold more than outweighs poor landings from some trips, i.e. in a comparison between two alternatives the one with the lower expected mean value is preferred thanks to higher variation.

In an analysis of individual trip decisions the relevant costs are those related to variable factors, mainly fuel and labor. However, data on these cost categories are not available for the present study. We are therefore forced to use the moments of revenue instead of short-run (variable) profit in the gear choice model. Use of revenue instead of profit in a gear choice model will not lead to biased results if variable costs are small or not influenced by gear choice (e.g. similar amounts of fuel are consumed in shrimp and cod fisheries for a particular boat), or if labor income is to a large degree a 
function of revenue. Since all of these factors are relevant to the Swedish trawl fisheries we believe that revenues are highly correlated with profits.

The model framework above describes a single-output technology. In fisheries several different species may be caught, even though the gear is aimed at a particular species, as is the case in our empirical study. In this respect we are dealing with a multi-output technology. However, the possibility of differentiating between different species is small once the gear type is chosen. With the chosen gear for the target species, the fisher has limited ability to influence the amount of by-catches of other species, and the species composition of the by-catch.

A linear quadratic form is used for the mean function $g(\cdot)$.

An advantage of the linear quadratic specification is that the firm specific effect on mean output is additive, i.e. $\mathrm{E}\left(y_{i t}\right)=g\left(\mathbf{x}_{i t}\right)+\mu_{i}+u_{i t}$, which is a requirement for the JustPope model. However, a potential drawback is that the mean output difference is constant in input levels.

Separate JP production functions are estimated for each of the three types of gear. The parameters are estimated using data from individual fishing trips of 47 demersal trawl vessels in 1995. Ideally, we would estimate the effects of vessel capacity separately. Unfortunately, we have an identification problem since our proxies for these variables are constant for each vessel. To capture the effect of these variables simultaneously we choose to use vessel-specific fixed effects. Our mean production function is specified as

$$
\begin{aligned}
Y_{i t} & =\alpha_{H} H_{O U R S}+\alpha_{H H} H_{\text {OURS }}{ }^{2}+\alpha_{H G} \mathrm{HOURS}_{i t} G R T_{i}+\Sigma_{m=2,12} \alpha_{m} D_{m} \\
& +\sum_{i=1,47} \alpha_{i} V_{i}+u_{i t}
\end{aligned}
$$

where $Y_{i t}$ is the landing value in Swedish currency (SEK) by the $i$ th vessel per $t$ th trip, HOUR is fishing effort in hours, GRT is vessel capacity in gross registered tons, $D_{m}$ is dummy variables for month $m$, where one month is dropped to avoid the dummy variable trap, $V_{i}$ is dummy variables for vessel, and $u_{i t}$ is the error term. The interaction term HOURS.GRT is included to capture the fact that large vessels have a higher fishing capacity per hour than small vessels.

In the second stage the parameters of the variance function are estimated. The variance function $\operatorname{Var}(u)=h(\cdot)$ used, is a special case of Harvey's (1976) variance 
function specification $\operatorname{Var}(u)=h(\mathbf{z})=\exp [\mathbf{z} \boldsymbol{\delta}]$, where the $\mathbf{z}$ 's are input levels or transformations of input levels, e.g, logarithms of inputs and second-order terms. ${ }^{6}$ The variance function is specified as:

$$
\begin{aligned}
& \operatorname{var}\left(u_{i t}\right)=\exp \left(\delta_{H} \text {HOURS }_{i t}+\delta_{H H} \text {HOURS }_{i t}{ }^{2}+\delta_{H G} \mathrm{HOURS}_{i t} \cdot G R T_{i}+\sum_{m=2,12}\right. \\
& \left.\delta_{m} D_{m}+\Sigma_{i=1,47} \delta_{i} V_{i}\right)
\end{aligned}
$$

We use the predicted mean and standard deviation of revenue, i.e. $E(Y)=x \hat{\alpha}$ and $S D(Y)=\sqrt{\exp (z \hat{\boldsymbol{\delta}})}$ from the estimated JP functions as explanatory variables in the gear choice model. The first-stage OLS estimates of $\alpha$ are unbiased despite the heteroskedasticity of the error term, and will therefore provide unbiased estimates of $E(Y)$. The mean and standard deviation is evaluated in the observation values of the regressors.

\section{Discrete Choice Analysis}

When agents are confronted with a finite number of discrete alternatives, a feasible way of modeling these agents' behavior is discrete choice analysis. Relying on the principle of utility maximization, agents are assumed to choose the alternative that maximizes their utility at the time of the choice. One fruitful approach is the concept of random utility, which considers the true utilities of the alternatives to be random variables implying that the probability for an alternative to be chosen is defined as the probability of it having the greatest utility among the available alternatives (Ben-Akiva and Lerman, 1985). The standard approach when applying discrete choice random utility models for more than two choices has been the multinomial logit (MNL) model (McFadden, 1973). An advantage with the MNL model is that choice probabilities are easy to calculate. A potential drawback is the restrictive assumption of independence of irrelevant alternatives (IIA), which in our study would imply that a change in the attributes of one type of gear requires proportional changes in the probabilities associated with the alternative type of gear. The mixed $\mathrm{MNL}^{\square}$ (hereafter random-parameters logit)

\footnotetext{
6 The first element of $\mathbf{z}, z 0$, is taken as unity. This implies that $\operatorname{Var}(\varepsilon)=\exp \left(\delta_{0}\right)$. The equation that is actually estimated to obtain the parameters of the variance function is $\ln \left(\hat{a}^{2}\right)=\mathbf{z} \boldsymbol{\delta}$, where $\hat{a}=\mathrm{Y}-\mathbf{x} \alpha$, and $\alpha$ are the estimated parameters from the first stage.

${ }^{7}$ Several names for these models occur in the literature, e.g. random-coefficients logit, random-parameters logit, error-components logit, and "probit with a logit kernel" (Revelt and Train, 1998).
} 
introduced by Boyd and Mellman (1980), and Cardell and Dunbar (1980) does not exhibit this restrictive forecast pattern. Further, the random-parameters logit approach renders possible a model which allow risk preferences to vary by fishers.

We now turn to the specification of the gear choice model. Skippers are assumed to choose among several discrete alternatives. The number of choice situations can vary by skipper, and the number of actual alternatives can vary by skipper. We observe the choice made and assume that this choice generates the highest utility for them. For the $\mathrm{n} t h$ skipper faced with $\mathrm{J}_{\mathrm{n}}$ alternatives, suppose that the utility of alternative $\mathrm{j}$ is $U_{\mathrm{jn}}=\beta_{\mathrm{n}} \mathbf{x}_{\mathrm{jn}}+\epsilon_{\mathrm{jn}}$ where $\mathbf{x}_{\mathrm{jn}}$ is a vector of observed variables. The coefficient vector $\beta_{n}$ is unobserved for each $n$ and varies by fisher with density $f(\beta \mid \theta)$ where $\theta$ are the true parameters of this distribution (e.g. the mean and the standard deviation of $\beta$ ), and $\epsilon_{\mathrm{jn}}$ is an unobserved random term that is an independent, identically distributed extreme value, independent of $\beta_{\mathrm{n}}$ and $\mathbf{x}_{\mathrm{jn} .}{ }^{8}$ Conditional on $\beta$, the probability that skipper $\mathrm{n}$ chooses gear $\mathrm{j}$ can be expressed as:

$$
L_{i(n) n}(\beta)=\frac{e^{\beta x_{i(n) n}}}{\sum_{j \in e^{\beta}} x_{j(n) n}}
$$

The unconditional probability is the integral of the conditional probability over all possible values of $\beta_{n}$, which depends on the parameters of the distribution of $\beta$ :

$$
P_{i(n) n}(\theta)=\int L_{i(n) n}(\beta) f(\beta \mid \theta) d \beta
$$

Our objective is to estimate $\theta$, i.e., the population parameters that describe the distribution of individual parameters. The $\log$-likelihood function is $\operatorname{LL}(\theta)=\Sigma_{\mathrm{n}} \ln$ $\mathrm{P}_{\mathrm{i}(\mathrm{n}) \mathrm{n}}(\theta)$. Exact maximum likelihood estimation is not possible since the integral in equation (8) cannot be calculated analytically. Instead, the probability is approximated through simulation and the simulated log-likelihood function is then maximized (Train,

\footnotetext{
${ }^{8}$ The model is easily extended to a panel data approach (see Train, 1999a). As the panel model did not converge for our data set, we estimate a cross-section model where fishers make repeated choices but no
} 
$1999 b) . P_{i(n) n}(\theta)$ is approximated by a summation over randomly chosen values of $\beta$. For a given value of the parameters $\theta$, a value of $\beta$ is drawn from its distribution. In our estimation, we use 1000 repetitions with Halton sequences, which are expected to be superior to random draws (Train, 1999b). If the random coefficients are independently and normally distributed, the coefficient vector can be written $\beta_{\mathrm{n}}=\beta+\mathrm{Q} \eta_{\mathrm{n}}$, where $\mathrm{Q}$ is a diagonal matrix of standard deviations, with elements of zeros for the fixed coefficients, and $\eta_{\mathrm{n}}$ is a vector of independent standard normal deviates. The coefficients $\beta$ and $Q$, representing the mean and the standard deviation of $\beta_{n}$, are estimated.

To apply the model, we need to specify a functional form for utility. The original paper by Bockstael and Opaluch (1983) used a logarithmic utility function. This is a very restrictive function as pointed out by Mistiaen and Strand (2000), who suggested a quadratic utility function. However, quadratic utility implies nonmonotonicity in wealth in some ranges, and the unlikely preference structure of increasing absolute risk aversion (Saha, Shumway, and Talpaz, 1994). Instead we suggest a linear utility function in the mean-standard deviation framework, which given that the decision problem satisfies Meyer's location-scale condition - yields consistent ranking with expected utility (Bar-Shira and Finkelshtain, 2000). The slope of the indifference curve in the $(\sigma-\mu)$ space is defined by

$$
S(\mu, \sigma) \equiv-\left(V_{d} / V_{\mu}\right)
$$

where subscripts denotes the partial derivatives. Meyer (1987) has shown that various hypotheses concerning risk aversion measures in the expected utility setting can be translated into equivalent properties concerning $V(\mu, \sigma)$ :

i) Risk aversion, neutrality and affinity correspond to $S(\mu, \sigma)>0,=0$, and $<0$, respectively.

ii) The magnitude of $S(\mu, \sigma)$, when positive, reflects the degree of risk aversion.

restriction is placed on each fisher's sequence of choices. This results in consistent, but not efficient estimates. 
iii) Decreasing, constant, increasing absolute risk aversion corresponds to $S_{\mu}<0,=0$, > 0 , respectively.

For a linear representation we have that

$$
V(\mu, \sigma)=\mathrm{b}_{1} \mu+\mathrm{b}_{2} \sigma
$$

where $V_{\mu}=\mathrm{b}_{1}$ and $V_{\sigma}=\mathrm{b}_{2}$. This implies that if $\mathrm{b}_{1}$ is positive, fishers' risk attitude will be reflected by the sign of $b_{2}$; for instance, a negative value for $b_{2}$ implies risk aversion in accordance with $i)$. Further, if $b_{2}$ is assumed to be a random parameter, we allow for heterogeneous risk preferences among fishers. This means that the size of the risk premium, i.e. the wedge between risk neutral and risk averse decisions, is allowed to vary across fishers. We also see that $S_{\mu}=0$, i.e. there is an a priori restriction of Constant Absolute Risk Aversion (CARA), which also implies Increasing Relative Risk Aversion (Saha, 1997). To assume CARA is not ideal since there is substantial evidence from empirical research in favor of Decreasing Absolute Risk Aversion (Saha, 1997). However, it has often been employed in empirical research in agriculture (Coyle, 1999). Further, our suggested functional form is tractable in an RPL model and, given that we lack good estimates of initial wealth for the fishers, CARA is advantageous in the sense that risk attitudes are independent of initial wealth levels.

Besides expected landing value, expected standard deviation of landings, and vessel attributes like GRT, one would also expect past behavior to be an important explanatory variable for predicting gear choice. Inertia in gear choices may be present due to technological constraints, costs of switching gear, or habit formation. The physical characteristics of the vessel determine whether all types of gear considered here can be used and some vessels may have invested only in one or two gears prior to the data period. Gear switching can be time-consuming and thus costly, since time is lost that could have been spent on the fishing grounds or in other activities. Some fishers may also have acquired knowledge and developed skills for particular fishing grounds where a certain species dominate, and thus be reluctant to target other species despite small catches on recent trips. Bockstael and Opaluch (1983) use an inertia variable, 
which only confirms if the same choice is made for the two years they study, and find it highly significant. Such a variable cannot be used for prediction and instead we define lagged variables, which refer to the gear employed in the previous trip. However, estimating lagged variables in discrete panel data is problematic, and severe bias can arise due to either true state dependence or spurious state dependence (Heckman, 1981a, b). However, Chintagunta, Kyriazidou, and Perktold (1999) report Monte Carlo simulation results, and find that conditional logit with a lagged dependent variable, which they label as feedback parameter, produces small bias on the $\beta$ coefficients, but the feedback parameter is significantly underestimated towards zero.

\section{Data}

The Swedish National Board of Fisheries collected the data used in this study. The log book database identifies vessel, fishing effort, gear type and landing date on a per trip basis, while the sales book database contains vessel, landing date and gross revenue. Location choice is reported in the log book, specifying a squared area of 30 times 30 nautical miles. These squares are too large to identify the sophisticated location choices that fishers make all the time, and most fishers in our sample fished the same area for all their trips. Unfortunately, this rules out the possibility of bringing in location choice to the fishers' decision problem, which is done in e.g. Eales and Wilen (1986).

The National Board of Fisheries Data provided data on 40 vessels, and data on 61 vessels existed from a previous study on trawlers specializing in Norway lobster. It was found that that a large fraction of the vessels only targeted one species during the year, but also that almost all of the others only used two of the three types of gear. Information on which gear each vessel had in possession was not available and the potential choice set for each vessel was determined on the basis of what gear they had

\footnotetext{
${ }^{9}$ Honoré and Kyriazidou (2000) suggest an approach, which we unfortunately did not find tractable for our empirical purposes.

10 The link between the two databases is the landing date. In a minor number of cases it does not provide a perfect match, and corrections were carried out. A potential risk of slightly changing the data characteristics cannot be excluded.
} 
actually employed. All vessels recording use of only one gear were dropped. ${ }^{\text {The final }}$ data set consists of 3762 observations. Summary statistics are presented in table 1 . The 47 vessels are fairly representative of the whole fleet with a median size of 50 GRT, median age 35 years, and a crew of one, two, or three persons including the skipper. Commercially available software is used to estimate the parameters of the models.

Table 1 Summary statistics ${ }^{\mathrm{a}}$

\begin{tabular}{lllll}
\hline Variable $^{\mathrm{a}}$ & Mean & shrimp & lobster & cod \\
\hline No. of observations (3762 total) & - & 1118 & 2019 & 625 \\
Revenue (SEK/trip) & 12080 & 14850 & 10690 & 11610 \\
& $(11080)$ & $(12290)$ & $(9970)$ & $(11320)$ \\
Fishing effort (hours/trip) & 12 & 14 & 11 & 13 \\
& $(7.9)$ & $(8.3)$ & $(7.4)$ & $(8.3)$ \\
Landing value per unit effort (SEK) & 1060 & 1150 & 1023 & 1002 \\
& $(906)$ & $(968)$ & $(825)$ & $(1025)$ \\
& & & & \\
Gross Registered Ton (GRT) & 53 & 60 & 53 & 43 \\
& $(28)$ & $(33)$ & $(25)$ & $(23)$ \\
\hline Predicted Values & & & & \\
Revenue (SEK/trip) & 11720 & 12550 & 11530 & 11110 \\
& $(8290)$ & $(8760)$ & $(8030)$ & $(8290)$ \\
SD of Revenue (SEK/trip) & 6590 & 6910 & 5950 & 7550 \\
& $(4360)$ & $(3190)$ & $(4420)$ & $(5660)$ \\
\hline
\end{tabular}

a) Standard deviations in brackets

\section{Empirical Results}

The fixed effects production functions were estimated by OLS and the estimated coefficients were then used to generate expected revenues for the potential gear choices for each observation. The logarithm of the squared difference between predicted values and actual values were then regressed upon the same variables as in the mean function. The obtained coefficients were corrected for heteroscedasticity (Harvey, 1976) and used to generate predicted variances. The mean revenue functions had adjusted $\mathrm{R}^{2}$ of 0.80 , 0.79 , and 0.74 , for shrimp, lobster, and cod, respectively. Exclusion of the vessel

\footnotetext{
${ }^{11}$ We included vessels where the second gear was used more than $5 \%$ of the total trips during the year. Use of a third gear was only recorded in 23 trips and never met the $5 \%$ criterion.

${ }^{12}$ We use LIMDEP ${ }^{\mathrm{TM}}$, from Econometric Software Inc, for the logit models.
} 
dummies was firmly rejected by F-tests at the $1 \%$ level of significance. For the revenue risk functions the adjusted $\mathrm{R}^{2}$ was around 0.98 for all the three gear types. Again, the Ftests provided strong support for inclusion of the vessel specific effects. Our results indicate that homogeneous revenue functions ignore substantial heterogeneity in the fleet and, would in our case produce misleading results. In fact, using average revenue functions in the standard logit model, lead to predictions with less accuracy than random guesses.

We now turn to the logit models, where the standard MNL model serves as a benchmark for the RPL model. The generated predictions of mean revenues and revenue standard deviations are alternative specific attributes. The standard deviation coefficient is assumed to be random with a normal distribution, while we specify the mean revenue coefficient to be fixed. ${ }^{3}$ The gear employed in previous trip and the vessel sizes are firm specific characteristics.

\footnotetext{
${ }^{13}$ Both lognormal and normal specifications for the mean coefficient were tested, but lead to insignificant standard deviation and failure to reach convergence, respectively. Panel data models were also tested, but failed to reach convergence.
} 
Table 2. Standard and Random Parameters Logit results ${ }^{\mathrm{a}}$

\begin{tabular}{llll}
\hline & & Standard Logit & Panel data RPL \\
Expected mean revenue & Mean coefficient & $1.648^{* * *}$ & $1.771^{* * *}$ \\
& & $(0.289)$ & $(0.306)$ \\
Expected SD of & Mean coefficient & $-0.985^{* * *}$ & $-1.242^{* * *}$ \\
revenue & & $(0.289)$ & $(0.323)$ \\
(Normally distributed) & & & \\
& SD of coefficient & - & $2.484^{* * *}$ \\
& & & $(0.502)$ \\
Constant: & Shrimp & $-3.165^{* * *}$ & $-3.418^{* * *}$ \\
(Cod is reference alt.) & & $(0.440)$ & $(0.466)$ \\
& Lobster & $-1.933^{* * *}$ & $-2.073^{* * *}$ \\
& & $(0.190)$ & $(0.204)$ \\
GRT & & $0.012^{* * *}$ & $0.013^{* * *}$ \\
& & $(0.004)$ & $(0.004)$ \\
GRTimp & & $0.008^{* *}$ & $0.009^{* *}$ \\
& & $(0.003)$ & $(0.004)$ \\
Shrimp |(t-1)=shrimp & & $4.457^{* * *}$ & $4.991^{* * *}$ \\
& & $(0.713)$ & $(0.817)$ \\
Shrimp |(t-1)=lobster & $2.836^{* * *}$ & $3.104^{* * *}$ \\
& $(0.408)$ & $(0.434)$ \\
Lobster|(t-1)=lobster & $3.816^{* * *}$ & $4.047^{* * *}$ \\
& $(0.152)$ & $(0.176)$ \\
Lobster|(t-1)=shrimp & $1.363^{* * *}$ & $1.691^{* *}$ \\
& $(0.636)$ & $(0.735)$ \\
Log likelihood function & -1314 & -1307 \\
Pseudo-R ${ }^{2}$ & 0.682 & 0.684 \\
\hline
\end{tabular}

a) Standard errors in brackets. The two parameters mean revenue and SD of revenue are scaled by 0.000005 .

**Significant at $5 \%$ level. ***Significant at $1 \%$ level.

The results of the standard logit model and the random-parameters logit model are presented in Table 2. Most of the estimated coefficients are significant at the $1 \%$ level. In the RPL model, the estimated standard deviation of the coefficient is highly significant, indicating that the parameter does indeed vary in the population of fishers. The estimated values for mean and standard deviation for expected standard deviation in landings implies that $70 \%$ of the fishers exhibit risk aversion, while $30 \%$ of the fishers exhibit risk neutrality or risk affinity. Since the variance in the error term in the standard logit is greater than the variance in the extreme value component of the error component in the RPL model, normalization is expected to make the parameters in the RPL to be of greater magnitude than in the standard logit (Revelt and Train, 1998), which is 
confirmed by our results. However, the rise in magnitude is moderate, indicating that the random parameters only represent a minor share of the variance in the unobserved utility. We also find, based on the slight change in pseudo- $\mathrm{R}^{2}$, that the RPL model does not provide a major difference in explanatory power compared to the standard logit. 14 The positive and significant values of the coefficients GRT $_{\text {shrimp }}$ and GRT $_{\text {lobster }}$ indicate firstly, that the vessel size is a determinant for choice as in the studies of Bockstael and Opaluch (1983) and Dupont (1993), and secondly, that the larger the vessel the higher the probability of targeting shrimp and lobster compared to the reference alternative cod. The dummy variables Shrimp $\mid(t-1)=$ shrimp and Shrimp $\mid(t-1)=$ lobster reflects the tendency for choosing shrimp depending on target species on the previous trip. Analogously, the same follows for the Lobster dummy variables where cod is again the reference alternative. We find a strong tendency in keeping the same gear as was used on the previous trip.

Table 3. Elasticities of probabilities with respect to expected landing value (RPL)

\begin{tabular}{llll}
\hline & Gear & & \\
Attributes in & shrimp & lobster & cod \\
shrimp & $\mathbf{0 . 2 3}$ & -0.23 & -0.01 \\
lobster & -0.32 & $\mathbf{0 . 4 7}$ & -0.15 \\
cod & -0.01 & -0.26 & $\mathbf{0 . 2 6}$ \\
\hline
\end{tabular}

Tables 3 and 4 present the elasticities of the probabilities for the RPL model, for expected landing value and expected standard deviation, respectively. These estimates indicate that fishers do react to changes in these variables, but considerable changes are required to induce a change from using the same gear as used in the previous trip. For example, if expected landing value for shrimp increases by $1 \%$, the probability of choosing lobster decreases by $0.32 \%$, and correspondingly an increase in expected standard deviation by $1 \%$ for lobster will reduce the probability of targeting lobster by $0.16 \%$. Most of the vessels alternate between lobster, and either shrimp or cod, while cod and shrimp is a rare combination. Given this, the negligible effects between cod and

$\overline{14}$ The pseudo- $\mathrm{R}^{2}$ is calculated as $1-(\log$-likelihood of model/log-likelihood at all betas $=0)$. 
shrimp, and vice versa, seem plausible as well as the asymmetric values in cross elasticities.

Table 4. Elasticities of probabilities with respect to expected standard deviation (RPL)

\begin{tabular}{llll}
\hline & Gear & & \\
Attributes in & shrimp & lobster & cod \\
shrimp & $\mathbf{- 0 . 0 8}$ & 0.08 & 0.00 \\
lobster & 0.10 & $\mathbf{- 0 . 1 6}$ & 0.06 \\
cod & 0.00 & 0.06 & $\mathbf{- 0 . 0 6}$ \\
\hline
\end{tabular}

Finally, we find that the estimated mean value of $S(\mu, \sigma)=-\left(V_{\sigma} / V_{\mu}\right)$ is equal to 0.7, which is similar to the results for agricultural production in Saha (1997) and within the range of the results from a number of different studies referred by (Saha, Shumway and Talpaz, 1994). This measure of risk aversion states that fishers on average will choose an alternative with a one unit higher expected mean, given that the increase in expected standard deviation does not exceed 0.7. Applying these values to our predicted trip values, indicate that a trip with mean SEK 12700 (8900) is preferred to one with mean SEK 11700 (8300), standard deviation in brackets.

\section{Discussion and Conclusion}

In this paper we have studied the fishers' supply response decisions under uncertainty as applied to the gear choice of Swedish demersal trawlers. Our results indicate that the fishers in our sample consider both expected revenue and revenue variability when choosing gear. Given that aiming for any of the three different species does not imply significantly different cost structures, fishers in our sample exhibit positive marginal utility in expected profit, and a great majority exhibit negative marginal utility in profit risk, i.e. risk aversion. The latter is important since it is of widespread anecdotal belief that the risky nature of fishing implies that fishers are risk lovers, a view which 
occasionally has gained support in the literature (Dupont, 1993). However, in line with previous studies on this topic we find a strong inertia effect. Given the magnitude of the estimated elasticities for the different variables, it would require considerable variability in expected revenues to induce gear change of fishers in many cases. This result supports those of Bockstael and Opaluch (1983), that a threshold to change exists due to monetary conversion costs, non-monetary factors, and personal preferences. It may also be true that fishers have a rationale for not switching too often, which we have not been able to model. This could be due to some kind of short term learning effect, i.e. fishers learn from each trip and are able to exploit this knowledge given that they don't change gear. The inertia to changes and the potential gains from not switching are important pieces of information for policy makers. Weitzman (2000) argues that, given uncertainty in recruitment, a Warming landing tax ${ }^{15}$ always performs better than an ITQ solution. If fishers do not change their behavior in line with varying tax rates, due to different recruitment, some stocks may be severely depleted before the desirable effort reduction is achieved. It could also be the case in such a setting that valuable knowledge among fishers would be lost as some of them would be driven out of business during a period of high taxes, and when conditions improve a tax reduction would not lead to the desirable increase in landings.

The explanatory power of the estimated stochastic revenue functions used in this study was significantly improved when vessel dummies were included. In the standard logit model, using average revenue functions lead to predictions with less accuracy than random guesses. Holland and Sutinen (2000) estimated positive values on the parameters on coefficient of variation of average revenues, indicating risk loving behavior, but held that fishers in their sample rather tried to reduce risk in other ways. Our empirical results indicate that homogeneous revenue functions ignore substantial heterogeneity in the fleet and, hence may produce misleading results. The rejection of pooled intercepts in the mean revenue functions and revenue risk functions gives support for the existence of considerable skipper skill, which is often discussed in the literature (e.g. Kirkley, Squires and Strand, 1998; Coglan and Pascoe, 2000).

\footnotetext{
${ }^{15}$ An optimal tax, often referred to as a Pigovian tax thanks to Pigou (1920) who suggested it as a correction for emission externalities, which Warming (1911) suggested as a correction for the fishers' tendency to over-exploit a fishing ground.
} 
Exercising direct controls on total effort may in many fisheries imply prohibitively high monitoring and enforcement costs, which suggests that more research effort should be spent on modeling fishers' supply response decisions. Our results show that a majority of the fishers in our sample respond negatively to increased variability in expected revenues, but also stress the importance of accounting for the heterogeneity among fishers. Besides a positive response to increased mean revenue and negative response to increased standard deviation of revenue, the inertia to switch is an important determinant factor. In this study we lack information on actual costs for switching gear and additional information on non-monetary factors for not switching. Hence, we cannot assess the trade-off between expected revenue and revenue variability on the one hand and transaction costs for switching gear on the other. Addressing these issues seems like an obvious task for future research.

\section{References}

Bar-Shira, Z. and I. Finkelshtain. 1999. Two-moments decision models and utilityrepresentable preferences. Journal of Economic Behavior \& Organization 38: 237-244.

Ben-Akiva, M. and S.R. Lerman. 1985. Discrete Choice Analysis, Cambridge, MA: MIT Press

Bockstael, N. and J. Opaluch. 1983. Discrete Modeling of Supply Response under Uncertainty: The Case of the Fishery. Journal of Environmental Economics and Management 10(2): 125-37.

Boyd, J. and R. Mellman. 1980. The Effect of Fuel Economy Standards on the U.S. Automotive market: An Hedonic Demand Analysis, Transportation Research, 14A(5-6): 367-378.

Cardell, N. and F. Dunbar. 1980. Measuring the Societal Impacts of Automobile Downsizing, Transportation Research, 14A(5-6): 423-434.

Chintagunta, P., E. Kyriazidou, and J. Perktold. 1999. Panel Data Analysis of Household Brand Choices. Unpublished manuscript, Department of Economics, Harvard University.

Coglan, L. and S. Pascoe. 2000. The contribution of unmeasurable inputs to fisheries production: an analysis of technical efficiency of fishing vessels in the English Channel. Unpublished manuscript.

Coyle, B. T. 1999. Risk Aversion and Yield Uncertainty in Duality Models of Production: A Mean-Variance Approach. American Journal of Agricultural Economics 81 (August):553-567.

Dupont, D.P. 1993. Price Uncertainty, Expectations Formation and Fishers' Location Choices. Marine Resource Economics 8(3): 219-47. 
Eales, J. and J.E. Wilen. 1986. An Examination of Fishing Location Choice in the Pink Shrimp Fishery. Marine Resource Economics 2(4): 331-51.

Eggert, H. 2000. "Technical effiency in the Swedish Nephrops Trawl Fishery for Norway lobster" paper presented at the IIFET 2000 conference, in Corvallis, Oregon, USA, July 10-14, 2000.

Eggert, H. and M. Ulmestrand, 1999. A Bioeconomic Analysis of the Swedish Fishery for Norway lobster (Nephrops norvegicus). Marine Resource Economics 14:225-244

Gordon, H.S. 1954. The economic theory of a common property resource: the fishery. Journal of Political Economy 62:124-142.

Harvey, A. 1976. Estimating Regression Models with Multiplicative Heteroscedasticity. Econometrica, 44, pp.1029-1054.

Heckman, J.J. 1981. Statistical Models for Discrete Panel Data. Ch.3 in Structural Analysis of Discrete Data, eds. C. Manski and D. McFadden. Cambridge, MA: MIT Press.

Heckman, J.J. 1981. The Incidental Parameters Problem and the Problem of Initial Conditions in Estimating a Discrete Time-Discrete Data Stochastic Process. Ch.4 in Structural Analysis of Discrete Data, eds. C. Manski and D. McFadden. Cambridge, MA: MIT Press.

Holland, D.S. and J.G. Sutinen. 1999. An Empirical Model of Fleet Dynamics in New England Trawl Fisheries. Canadian Journal of Fisheries and Aquatic Science 56(2): 253-64.

Holland, D.S. and J.G. Sutinen. 2000. Location Choice in New England Trawl Fisheries: Old Habits Die Hard. Land Economics 76 (Feb): 113-149.

Honoré, B.E. and E. Kyriazidou. 2000. Panel Data Discrete Choice Models with Lagged Dependent Variables. Econometrica Vol. 68(4):839-874.

Just, R.E. and R.D. Pope. 1978. Stochastic Specification Production Functions and Economic Implications. Journal of Econometrics 7:67-86.

Kirkley, J.E., D. Squires, and I.E. Strand. 1998. Characterizing managerial skill and technical efficiency in a fishery. Journal of Productivity Analysis, 9:145-160.

Leathers, H. D., \& Quiggin, J. C. 1991. Interactions Between Agricultural and Resource Policy: The Importance of Attitudes toward Risk. American Journal of Agricultural Economics, 73, 757-64.

Levy, H. 1989.Two-Moment Decision Models and Expected Utility Maximization: Comment. American Economic Review, 79(3), 597-600.

Meyer, J. 1987. Two-Moment Decision Models and Expected Utility Maximization. American Economic Review, 77(3), 421-30.

McFadden, D. 1973. Conditional logit analysis of qualitative choice behavior. In Frontiers in econometrics, ed. P. Zarembka. New York: Academic Press, pp.105-42.

Mistiaen, J. A., and I. E. Strand. 2000. Location Choice of Commercial Fishermen with Heterogeneous Risk Preferences. Amer. J. Agr. Econ. 82(5):1184-1190.

Pigou, A.C. 1920. The Economics of Welfare. New York: MacMillan.

Revelt, D., and K. Train. 1998. Mixed Logit with Repeated Choices: Households' Choices of Appliance Efficiency Level. Review of Economics and Statistics 80(November):647-57 
Saha, A., C. R. Shumway, and H. Talpaz. 1994. Joint Estimation of Risk Preference Structure and Technology Using Expo-Power Utility. American Journal of Agricultural Economics 76(May):173-184

Saha, A. 1997. Risk Preference Estimation in the Nonlinear Mean Standard Deviation Approach. Economic Inquiry 35(October):770-782.

Smith, V.L. 1968. Economics of Production from Natural Resources. American Economic Review 58:409-431.

Train, K. 1998. Recreation Demand Models with Taste Differences over People. Land Economics 74(May):230-39.

Train, K. 1999a. Mixed Logit Models for Recreation Demand, in Herriges, J.A. and C.L. Kling, eds., Valuing Recreation and the Environment: Revealed Prererence Methods in Theory and Practice, Cheltenham: Edward Elgar.

Train, K. 1999b. Halton Sequences for Mixed Logit. Working Paper, University of California, Department of Economics.

Ward, J.M. and J.G. Sutinen. 1994. Vessel Entry-Exit Behavior in the Gulf of Mexico Shrimp Fishery. American Journal of Agricultural Economics 76(Nov): 91623.

Warming, J. 1911. Om grundrente af Fiskegrunde. (On Rent of Fishing Grounds), tr. P. Andersen (1983) History of Political Economy). Nationalökonomisk Tidsskrift 49:499-505.

Weitzman, M.L. 2000. Landing Fees vs Harvest Quotas with Uncertain Fish Stocks. Paper presented at the IIFET 2000 conference, Corvallis, Oregon, USA, July $10-14,2000$.

Wilen, J.E. 1976. Common property resourcees and the dynamics of overexploitation: the case of the North Pacific fur seal. Department of Economics Research Paper No. 3. University of British Columbia, Vancouver. 